\title{
Living in Time's Shadow: Pollution, Purification and Fractured Temporalities in Buddhist Ladakh
}

\author{
Martin A. Mills
}

The time is out of joint: $\mathrm{O}$ cursed spite,

That ever I was born to set it right!

Shakespeare, Hamlet 1.5

The anthropology of time is a notoriously slippery topic, where abstract metaphysical speculation and concrete ethnographic analysis blur into one another with apparently effortless ease, so it is worth taking a moment to define the precise question that I'm interested in. ${ }^{1}$ Broadly, this paper follows in the footsteps of Geertz's famous work on 'Person, Time and Conduct in Bali', where he argued that Balinese social interaction was not comprised of individual personalities within durational time, but rather of 'generalised contemporaries' performing socially sanctioned offices. This, for Geertz, implied a 'depersonalized' notion of the person, in which the individuals become instantiated tokens of permanent persontypes within a 'motionless present' (Geertz 1973). This sense of a motionless present was derived from the use of non-durational calendrical systems, part of a broader Hindu-influenced cultural tendency to construct personhood in a manner which 'refuses to regard as salient ... the cumulative effects of historical time' (Gell 1992: 72).

Geertz's interpretation has not gone without criticism. Firstly, it has been argued that he veers too close to a monolithic interpretation of 'Balinese time' as non-durational, whereas in reality the Balinese evocation of calendrical systems is varied and multi-faceted (Davis 1976; Gell 1992; Howe 1981); and secondly, that his view of ritual calendars as a homogenous cultural resource mistakes ideology for cognition, thus ignoring the historical exercise of elite ideological power that support, and are supported by, structures of 'ritual time' that are at odds with the comparatively ideology-free 'practical time' of, for example, agricultural production (Bloch 1977).

Whilst both sides of this debate have clear and (varyingly) valid points to make (Gell 1992: Chs. 8-10), one dimension of this problem goes largely unaddressed. 


\section{Martin Mills}

While systems of time-reckoning are indeed ideologies embedded within particular structures of social power (e.g. Tannenbaum 1988), little space is given to the examination of time as a system of power in itself-as a means of actively integrating individual experience into social time, or, as Alfred Schutz put it, of unifying inner durée and outer (social) 'cosmic time' within a 'vivid present' (Schutz 1971). An analogy here will probably clarify the issue at hand. Medical anthropologists are reasonably au fait with the idea that particular medical ideologies serve to support the position of associated medical elites. However, anthropological critique since the 1970s has shown that it is insufficient to discuss such ideological hegemony solely in terms of the degree to which a particular population accept, or believe in, a certain ideology (Good 1994: Ch. 1). Rather, medical authority is primarily constructed within the embodied disciplines of the patient-healer relationship, in which a particular medical practitioner not only asserts the truth of a particular medical ideology (which may well be accepted by the patient), but asserts the reality of that truth within the particular case at hand. In other words, it is the act of diagnosis and treatment in a particular case, referring to particular patients which truly embeds those patients within a particular medical ideology, and designates the healer as not simply the peddler of accepted ideologies, but the authoritative creator of medical truths in particular social moments.

In much the same way, it is the particular act of integrating the individual into a general time scheme, rather than the acceptance of that scheme as a general abstract model, that marks the moment of real ideological hegemony. A simple example of such an act of integration can be seen within the European context of "national time', an idea most eloquently elaborated by Benedict Anderson in his picture of punctual daily acts of newspaper reading in the European world, a unification of an 'imagined' nation marching together through time (Anderson 1991: 35). Thus, just as when I check my watch against the chimes of Big Ben on the BBC or struggle to be on time for an appointment set according to it, it is not the validity of a temporal schema (such as a linear national time) that is in question, but my active, on-going integration into it - orientating me towards certain 'sources' of political and temporal authority - that marks true political hegemony on a local scale. This political engagement with 'official' (in this case, governmental) time is also an important part of the emergent construction of personhood: it is part of how I construct and orient a sense of my 'ordinary self' in terms of the world around me (Good 1994: 126; Schutz 1971: 212-22).

'Time anthropology' therefore involves two linked considerations: firstly, a more or less abstract examination of why people represent time in a particular way (and who might benefit from them doing so); and secondly, an examination of the embodied practices by which people do time - how they orientate themselves towards particular temporal/calendrical ideologies, and thereby integrate themselves into wider ideologically-structured communities. ${ }^{2}$ The distinction 
between these two elements is most clearly seen when social life renders them disjunct: when time becomes, to quote Hamlet, out of joint. This dis-articulation of the two components of 'time-ideology' leads to social moments and scenarios in which official time is symbolically 'stopped', fractured or rendered null and void. Such moments are more than Bloch's 'non-ritual time', since the values of ritual time are in no sense rejected. Rather, just as the quotidian orientation of the actor towards official time is an essential component of the construction of the 'ordinary self', so the 'fracturing' of time is most usually associated with moments in which the ordinary self is also fractured: moments of social death, radical personal transformation and generational transition. Despite a range of ethnographic possibilities it is difficult to surpass W.H. Auden's rendition of this combination in his poem Funeral Blues:

Stop all the clocks, cut off the telephone,

Prevent the dog from barking with a juicy bone,

Silence the pianos and with muffled drum

Bring out the coffin, let the mourners come.

The British tradition of stopping or covering up clocks upon a death in the family (e.g. Cohen 1985: 315) is perhaps one of the most obvious symbolizations of this kind of understanding, and of the social (and temporal) disempowerment that attends upon the mourning of families. In this case, such temporal disjunction attends upon families, a key but increasingly defunct economic unit in modern Britain. It is the argument of this paper that such integrative practices link varying kinds of embodied agent into wider 'official' time as social wholes. The precise contours of these 'embodied agents' varies from society to society, depending upon the manner in which cultures construct notions of social agency: the individual, the family, even communities as wholes. In what follows, I would like to look at this phenomenon in the context of pollution practices and astrological calendars amongst Tibetan Buddhist communities of Ladakh, North-West India - a society where the reproductive household is the primary collective agent of ritual life, and thereby of ritual time.

\section{Calendrical Systems in Buddhist Ladakh}

Since the early first millennium, Buddhist communities throughout Asia have used extensive and complex calendars to organize ritual and economic life. Within Tibetan Buddhist areas such as Ladakh, there is a tendency to use combined astrological (skar-tsis) and elemental (jung-tsis) systems, which link together celestial cycles with geomantic influences, often producing highly localized 
variants. Like their Thai and Shan counterparts (Davis 1976; Tannenbaum 1988), Ladakhi astrologers use a combined lunar-solar calculation of the year - such that the progression of twelve designated lunar months of thirty designated days is regularly re-adjusted to fit into the progression of the solar year - and are based on the calculation of the auspiciousness (tashi) and inauspiciousness (mi-tashi) of particular hours, days, months and years for certain kinds of activity. Whilst an analysis of Tibetan astro-elemental divination per se is impossible in one short essay, it can simplistically be broken down into two sets of cosmological discussions:

1. Astro-elemental calculations for interpreting the auspiciousness and inauspiciousness of actions relating to specific individuals of known birth-years and dates (Cornu 1997; Mumford 1989). These calculations are based on the complex temporal interaction of: cycles of male and female; cycles of animals; elemental cycles; planetary cycles (see below); the transformation of the eight signs of 'life-force' (sparkha), symbolised by eight trigrams (familiar from the Chinese I-Ching), denoting the auspiciousness of social forces and directions; and finally a numerological system (sme-ba), which determines the simple auspiciousness and malevolence of certain dates for certain people. Combined, these systems create a full cycle of either 180 or 360 years of non-identical birth calculations, composed of three lesser cycles of 60 years, to advise on the in/auspicious of certain kinds of activity for certain individuals (e.g. not travelling on business to the North and South-West on a specific day for fear of attack by demonic forces; or re-arranging the rooms in one's house on particular days in order to ensure recovery from illness). One of the most important usages for this system is the 'death horoscope' (Mumford 1989: 201-4), used to determine the cause of death and to look into the possible rebirths for the deceased.

2. More general cycles, indicating the auspiciousness and inauspiciousness of particular kinds of action on particular days throughout the year, month and week, applying as a rule of thumb to everyone (but in principle within the context of their birth calculations). Unlike person-specific calculations (which were made by professional astrologers (tsispa and onpo), these were widely known and accessible through household calendars. This occurs at three levels: (i) the yearly elemental cycle identifies certain months for certain kinds of activity: in spring Wood dominates (and so trees should not be cut), in summer Fire (so waterways can be constructed, because fire dominates water), in autumn Metal (so use of metal implements, such as for tree-cutting, is auspicious), and in winter Water (in its passive, ice mode); (ii) the monthly cycle of general tendencies (the waxing of the moon is good for expansive activities such as building, and the waning for destructive ones such as cutting down trees or finishing business); and (iii) 
the weekly cycle based on the seven planets (Mondays are auspicious days for planting, sowing seeds, expanding the family unit, astrology and divination; Fridays are auspicious for travel, temple-building and medical matters, whilst Sunday were generally inauspicious for these, etc.).

It would be inaccurate, of course, to view these simply as systems of prediction (Berzin 1991): firstly because, as Mumford points out (1989: 198-202), the interlocking cycles of astrological interpretation often produce conflicting results, requiring mediation by a ritual specialist (either an astrologer or a trained Buddhist monk), who will examine the different interpretations in terms of how clearly they agree with other elements of the specific case; and secondly, because particular influences can be modulated through ritual action. ${ }^{3}$ Therefore, the astro-elemental basis for Tibetan systems of divination should not be mistaken for a 'science' in the Western objectivist sense. In the case of elemental (jung-tsis) calculations, the elements - both individually and in conjunction - represent 'agents' or 'principles of transformation' (Cornu 1997: 52) that inform certain kinds of action within the world. More explicitly, astrological components are associated with founding Buddhas and deities, and the cycle of twelve animals (those kinds of 'pious' animal blessed by the Buddha at the time of his death) with the mobilization of certain kinds of 'personality' that influence those under their aegis.

In this respect, individuals and groups were felt to 'partake' of agencies already at work within the world, linking together time and socio-ritual agency. Thus, certain dates within the lunar cycle (new moon to new moon) were associated with the mythic activities of particular Buddhas or lesser Buddhist divinities: for example, the fifteenth day of the month (full moon) was associated with the acts of the Buddha Sakyamuni, the eighth day with those of the Medicine Buddha, the tenth day with Guru Rinpoche's vanquishing of the local gods, and so forth. On these days, prayers or rites to the commemorated deity are seen as being especially efficacious, and activities based on their 'role' seen to be more effective. The interlocution between time and social agency in such cases was often highly explicit: thus, the eighth day it was normal for village amchis (traditional doctors) to consecrate their medicines, thus rendering them more potent. Trained in the arts of the four medical tantric treatises, the amchi would visualize himself as being the Medicine Buddha (into whose lineage the amchi would have been ritually initiated) as the ritual basis for the consecration. Similar calculations attend much agricultural and nomadic activity, where the date of the first ploughing, of the movement of livestock to pastures, of going on trading journeys, are all regularly determined by astrological calculation (something which rather militates against Bloch's picture of 'practical' agricultural time). Here then, auspicious agency by social actors is seen as occurring in conjunction with a wider framework of divine and elemental agency within the world. As Roy Dilley argues, 'It is not so much 
that events are construed to repeat themselves by virtue of a circular conception of time and history, but rather that 'mythic' pasts and 'mythic' persons become synchronous with the present (Dilley, this volume). Time, then, is envisioned not so much as an empty abstract container for social action, but rather a sociallylegitimising resource for embodied actions, a legitimation (or auspiciousness) that must be 'sought out' by the ritual practitioner (whether astrologer, monk or farmer) through particular ritual practices and disciplines. In this picture of temporal progression, participation in time is unevenly deriving from relationships with sources of ritual power (called chinlabs, or 'blessing'), usually embodied in mythical, divine and semi-divine figures of the past. As Mumford notes: 'Tibetans compare chinlab to rain, but the source is the Buddha or the incarnate lama ... chinlab can be defined as traces left over from the primal era.' ${ }^{4}$

Ritual relations with sources of blessing in Buddhist Ladakh are mediated through a sacrificial economy organized around the dominant trope of the household (tr'ongpa) as both the principal source of the wealth (yang) and the principal object of ritual blessing (Mills 2003: 247-8). ${ }^{5}$ They are, in Bloch's words, 'the prime social, political and symbolic unit of the society. The house is the source of identity for the people who live in it and they, to a certain extent and in certain contexts, can be considered as together forming a single social actor' (Bloch 1992: 70, italics mine; see also Day 1989; Phylactou 1989). Households, and the territorial domains they represent, derive this single legal and social existence as corporate agents from their capacity to sponsor village-wide offering rites to crucial spirits and deities within the calendrical cycle. It is unsurprising therefore that they are the principal objects of concerns over ritual pollution and, I would argue, problems with the 'fragmentation' of ritual time.

\section{Pollution Practices in Buddhist Ladakh}

For Tibetan Buddhists of all traditions, the diametric opposite of blessing and auspiciousness is ritual pollution (dip), a concept distinct from, but linked to that of negative karma (mi-gyewa'i-las). Unlike karma, dip is seen as being localized to a single lifetime, curable through direct ritual and medical means, and unrelated to the intention of the polluted person (in the manner that karma classically is within Buddhist traditions). The term dip itself literally means 'shadow', as in the shade found on the dark northern side of a mountain. The analogy is a commonly used one, evoking images of landscape, light and height that are symbolic commonplaces within Tibetan Buddhist cultures. Sacred objects (such as religious texts) and persons (deity statues, monks, lamas and one's social and genealogical preceptors) are placed higher than oneself, and are seen as 'sources' (jung-sa) of blessing (chinlab). Here, the term jung-sa (place of arising) more colloquially 
refers to a mountain spring from which a stream runs downwards, but also implied 'sources' of social and religious knowledge and authority.

Much indigenous theorizing about dip by monks (for whom it was a topic in the Buddhist monastic curriculum) centred on this understanding of height and social authority. Thus, a monk at one of Ladakh's many monasteries explained that dip derived from 'things being upside down': thus, placing your sleeping mattress or your shoes (which should be beneath you) on your head would cause dip. At the same time, lack of respect for religious objects and teachers caused dip, implying as it did a certain arrogance (t'oman - literally, a claim to 'height'). Monks spoke of the inability to see one's religious teacher (lama) as a Buddha (one of the injunctions of Mahayana Buddhism) as resulting from 'the dip in one's mind'. In this sense, dip was caused by a shattering of established hierarchies, and the downwards flow of chinlab as the basis for auspicious action. At the same time, pollution was also created by commensality with impure castes and the misplacement of bodily fluids (e.g. saliva touching communal food).

A more powerful image, evoked in the case of birth and death pollution, is that of severance, often associated with people's relationship with local water-spirits $(l u)$ - earth-bound numina that are seen as the guardians of wealth and the source of human, animal and agricultural fertility, and which are therefore crucial aspects of the ritual elaboration of household life (see also Mills 2003: Ch.8). As with the many numina discussed above, their activity is seen to wax and wane throughout the year (awakening in the spring, being most active in the summer, and returning to sleep during the winter), throughout the lunar month (being most active during the first half, and waning in the second), and the across the week - cycles which are seen as linked to auspicious agricultural activity, and (as we shall see) to the auspiciousness and pollution linked to human reproduction. They are also seen as 'bound' to human activity by the powers of transcendent deities (such as Buddhas), and the acts of ritual practitioners. Disrespect for such water-spirits - such as urinating or defecating near their 'homes' (local springs), or digging up the soil without careful ritual precautions - was identified as the cause of powerful pollution and retribution from these important but capricious spirits.

Such dangers are particularly imminent in the processes of human reproduction. People's relations with $l u$ are treated as embodied within the reproductive nexus of the household: father, mother and growing foetus together - even the placenta is often ritually treated as a water-spirit, and subsequent to parturition is placed in the basement of the natal house, where such spirits reside. Indeed, the infant itself is seen - especially in its early stages of foetal growth - as existing more in the realm of the water-spirits than of humans. Parturition, and particularly the severing of the umbilical cord (usually by the husband) is therefore a violent sundering of the previously united nexus of fertility represented by the $l u$. The social agent involved in parturition - in this case, the household and its occupants 
- thus become deeply polluting to the water spirits, with whom they have - even if unavoidably - severed their relationship. A similar logic seemed to apply in the case of death pollution, caused by a severance of the individual from the fertile relationship of marriage (celibates such as monks do not incur pollution upon their death, and are seen as immune to its power). Members of households effected by pollution from birth and death were forbidden to enter fields or cross streams for fear of harming the water-spirits responsible for the harvest, and on pain of substantial fines from village councils. It is for this reason that there is a strongly expressed preference for both giving birth and dying in the winter, when the waterspirits sleep and the harvest cannot be harmed.

\section{Ritual Pollution and the Astrological Calendar}

As with most forms of ritual pollution, dip from such acts was seen as contagious and expansive in the context of ordinary social life. Passing through contact and commensality, it also 'fell' from human bodies to effect the land beneath them. The virulence of dip as a social force could be compared with the powerful images of social disempowerment that normatively adhered to the polluted. Here dip was seen as an 'obstruction' (barchad) to certain kinds of social and ritual action, causing a vulnerability to misfortune. Particularly with birth and death pollution, members of the same household were expected to stay indoors and refrain from cooking, from handling anyone's food but their own, from entering temples and giving offerings to the Three Jewels of Buddhism and local spirits (including the household and hearth gods), and from entering the fields. In effect, pollution undermined the capacity of householders to auspiciously perform all the principal functions of the household as a ritual, social and economic unit: it negated legitimate (or 'auspicious') social agency by disconnecting people from the sources (numinal and social) of that agency. Even in its lesser manifestations, dip is said to make people tired, lethargic, to produce an excess of sleepy dust, or in certain cases more serious cases to create unpleasant skin conditions or even paralysis (tsa-dip - 'root pollution'). Whatever happens, someone who is badly polluted is regarded as being confined in the broadest sense of the word - anything they do is seen as being doomed to failure or worse - better for them and others if they stayed at home.

Severe ritual pollution of this kind was seen to render victims incapable of participating through ritual exchange in the 'ordinary' divine powers embedded within the various astrological cycles; in this sense, it placed them 'outside' normal ritual time. Indeed, rather than their activities being seen as partaking in the blessings of various Buddhas and the good fortune and fertility of local spirits, the polluted (dipchan) are seen as embodying demonic action (for a comparison 
in Sri Lanka, see Kapferer 1983). Dip is seen as attracting demonic influence (gnodpa), such that any actions that the polluted perform are seen in this light, placing them 'outside' the ordinary astrological tempos that organize social life within village communities; moral history and time instead become 'demonic'. 6 During such times, actors become dislocated from ordinary life: in its most severe cases, pollution is seen to cause the life spirit $(l a)$ to leave the body, especially during twilight, and wander the barren interstices between human habitation, where demons dwell (cf. Tambiah 1976: 242). It also often opens the door to full-scale possession (lha-zhugs). This inversion of auspiciousness is a general characteristic of Tibetan understandings of deity. As Sophie Day comments: 'There is little to distinguish [dip] from the demonic. When the god is dirty, it causes harm, just like demons. When demons are cleaned and given homes, they cease their malevolence and become gods again' (Day 1989: 141). ${ }^{7}$ Certain temporal flows are therefore seen to emerge correctly from socially legitimate sources (Buddhas and local numina); others are not, and become demonic. Clearly then, with regard to Ladakhi Buddhist communities at least, analytical characterizations of pollution practices that ignore either their diachronous nature or their embodied relationship with sources of legitimation/'blessing', are in danger of bracketing out the very contagion and exclusion practices that have rendered the concept meaningful within anthropological discourse.

\section{Time and Pollution in Anthropological Theory}

The characterization of dip as produced by the movement of social actors to modes of personhood and temporality that are 'out of synch' with established sources of social agency is, of course, reminiscent of Douglas's famous characterization of dirt as 'matter out of place' (Douglas 1966: 56-7). However, despite the unsurprising nature of the ethnography surrounding Ladakhi understandings of dip within the wider South Asian context (its association with life cycle transitions, inter-caste relations, patterns of contagion, and its organization around sources of blessing are all features familiar to Hindu and Buddhist ethnographies) at the same time it demonstrates the paucity of synchronic structuralist characterizations of pollution. Douglas's 'category anomalies' are avoided in and of themselves - as inherently anomalous - and therefore have no emergent impact upon the world: to take an earlier example, placing a mattress on one's head may well be anomalous action which confuses established categories of social hierarchy (vide Douglas), but once removed, the anomaly should - according to Douglas's theory - disappear, presumably taking any associated pollution with it. Ethnographically, this is simply not the case: remove the mattress from one's head and the pollution that has been produced remains, requiring subsequent purification. 
Merely undoing the actions that cause pollution doesn't remove the pollution, because the pollution now exists as a newly emerged generative schema. To extend the 'sources' metaphor used by Ladakhis themselves, placing used eating utensils into a communal cooking pot creates a new and emergent arrangement of social categories in which the bodily contamination of the utensils becomes the 'source' of subsequently distributed food, rather than the ideal social source, the hearth-god. Those who eat from the polluted pot must share in the polluter's bodily essences - fine for the owner of the used utensil, all right for close family members (who are seen to share much of that essence already), but certainly no good for guests. Thus pollution lingers, even after its cause (whether a category anomaly or not) has been removed. Pollution is a form of social memory (see also Lambek 1992).

This diachronous quality to pollution behaviour - its tempo, in Bourdieu's (1972) terms - is what synchronous structuralist explanations such as Douglas's do not take into account, and thereby do not account for. This is all the more surprising given her famous emphasis on the 'abominations' of Leviticus, which makes persistent reference to the perduring qualities of uncleanness associated with contact with forbidden animals, XI: 24 . And by these ye shall become unclean; whoever touches their carcass shall be unclean until the evening, XI: 25. and whoever carries any part of their carcass shall wash his clothes and be unclean until the evening' (Leviticus XI: 24-25, quoted in Douglas 1966: 43, italics mine).

Adjusting for this in terms of anthropological theory means asserting that what is 'confused' in pollution are not objects of knowledge in a static world, but processes of socially-acknowledged emergent action in a world in which time not only marches on, but is the very context within which action is constituted. ${ }^{8}$ Specifically, Leviticus structures pollution within the cycle of the Hebrew day, which starts at evening: pollution is therefore removed through a combination of ritual cleansing and the renewal of the temporal cycle. Understanding this allows us to address a further question, implied within the ethnography above: if parturition destroys the embodied relationship that the household has with sources of fertility, thus producing pollution, how is it possible for the household group to become un-polluted, given that childbirth (and, of course death) are somewhat one-way processes?

\section{Purification Practices in Buddhist Ladakh}

In Buddhist communities in Ladakh, broadly similar rationales exist for the processes of purifying dip as for purifying uncleanness in Leviticus. Here, I shall discuss this in terms of purification practices surrounding birth. Generally, for the 
first seven days, father, mother and child are polluted (dipchan), and are confined to the house. During this period, the house may only be visited by male members of the household's p'aspun - a male-centred symbolic kin group comprising one or more nearby households who worship a single $p$ 'alha, or household god. ${ }^{9}$ One lunar week later, ${ }^{10}$ the father washes his lower body and monks visit the house to perform a purification ceremony (trus) and make offerings (sangsol) to the Buddhas, the household god and other local spirits. Following the performance of these rites, the father is free to leave the house, and non-p'aspun members can visit, bringing food and gifts (but not eating there). On the thirtieth day (that is, one lunar month later), the monks return to perform another trus on behalf of the mother, and a further sangsol offering. ${ }^{11}$ Thereafter, the house returns to normal functioning: non-p'aspun guests can eat there and touch the baby (Norberg-Hodge and Russell 1994); in my own fieldwork site, the child is traditionally taken by the father to be 'shown' to the household and local area gods at their shrines. ${ }^{12}$

Both trus and sangsol rites involve the evocation of divine figures (principally Buddhas), either to purify existing pollution or to re-establish relations between humans and a variety of local spirits (such as $l u$ ) following pollution events. In both cases, re-establishing a 'normal' state of affairs is seen as contingent on the ability of the ritual officiant (usually, but not always a member of the monastic community) to evoke the presence of particular Buddhas within the ritual process. Trus (literally, 'washing') rites focus on the use of the 'cleansing mirror' (L. trus melong - a circular brass plate mirror) and a water vase (L. bumpa). The vase is filled with water and consecrated through visualising the retinue and divine mansion of the celestial Buddha Dorje Namjom descending and dissolving into the water. The water is then poured over the face of the mirror as a series of Buddhist divinities are visualized entering a bathing-house (also visualized in the mirror by the officiant) and, being bathed there, further purifying the ritual water, which is then collected in a copper bowl beneath the mirror. Following this, the object or person to be purified is 'washed' again with the same water, thus removing the accumulated pollution. The 'dirty' (driwa) water running off the patient is finally collected and added to ground barley, which is then moulded into a $l u d$, or ransom-offering; this is then taken out of the house and left at a cross-roads to be consumed by demons (dre) and obstructive spirits (gye) that would otherwise have plagued the patient. One of the most important aspects of trus, which was strongly emphasized by the officiant, was that all present should strongly imagine the officiating monk to be the deity Dorje Namjom, and the patient is conversely instructed to visualize him or herself as Dorje Namjom's faithful disciple. It is only in the context of this 'faith' (dadpa) in themselves as the respective embodiment of religious teacher and pupil (lop-truk) that the rite is held to have any efficacy, and the 'patient' to be a recipient of the blessings of the Buddhas. 


\section{Martin Mills}

Similar transformations of social role occur in the sangsol offering rite, performed to re-establish the patient's relationship with the various divinities and spirits of the local and supra-local cosmos. Such rites have a variety of forms, depending principally upon who is performing them. When performed by laity on their own behalf, they take the form of simple supplications and offerings, entreating the relevant deities to act in the officiants' favour out of compassion, or in return for offerings given to the deities and spirits in question. In many cases, however, monks were employed to perform the rite, due to their tantric training within the various cycles of particular tutelary 'wrathful' Buddhas, whom (in a similar manner to the traditional doctor discussed earlier) they were thereby entitled to 'represent' in rites. Such rites evoked a mythic history of transcendent Buddhas vanquishing errant local spirits (such as $l u$ ), binding them to accept vegetarian Buddhist offerings and to do the bidding of the officiant. Such an invocation is not merely a summoning, but a reconstruction of the tutelary deity's original moment of magical triumph (Samuel 1993: 185-6), re-establishing a relationship of blessing between deities and the polluted household.

The performance of purificatory rites thus 're-inserts' individuals and households back into a numinal hierarchy from which they have been temporarily dislocated. Moreover, such 're-insertions' are framed within the rhythm of lunar calendrical cycles (one lunar week for the father, one lunar month for the mother). Groups thus resume ritual integration at the astrological point at which they left off, in terms of the cycles of shared ritual agency. The implication is that pollution events seem to segment temporal flows, producing a kind of 'shadow' or 'demonic time' that flows in tandem with ordinary social time, but is characterized by an emergent inauspiciousness which normatively disempowers polluted actors and discourages crucial forms of social action.

\section{Conclusion}

At the beginning of this analysis I argued that 'time-anthropology' should take note of two linked ideological processes: the intellectual expression of a particular temporal ideology (cyclic, linear or whatever) as a generally valid way of interpreting the world, on the one hand; and those ritualised practices which integrate embodied agents into that schema, on the other. This integration forms a 'vivid present', in Schutz's terms. What unifies these two elements, however, is not a discussion of time per se, but a discussion of legitimate social agency - a complex series of emergent processes that constitute social personhood. In the Ladakhi case, social and ritual agency is seen as fundamentally derivative, dependent on established ritual relationships between corporate social actors (such as households) and multiple 'sources' of blessing. These relationships cycle 
through time according to calendrical ideologies of divine agency, rendering specific moments as 'good for' certain kinds of action. In this regard, the mode of integration involved is very much an embodied one, linking the reproductive 'body' of the household to 'sources' of fertility $(l u)$ and those who can control them (the Buddhas) through sacrificial modes of exchange.

The logical result of this fulcrum of agential time and personhood is that certain moments exist in which the developmental processes of bodies also radically interrupt the established relationship between social agents (whether communal or individual) and sources of blessing. Such events and actions - most obviously, parturition and death - dislocate social agents from the established cycle of sources embedded within astrological and elemental time, generating pollution. ${ }^{13}$ The fragmentation of 'ordinary personhood' described above is of course constituted through modes of exchange and symbolism specific to Ladakhi ritual life. It is, however, worth suggesting that such crises are possibilities inherent within the wider phenomenology of embodied experience. Within medical anthropology, Byron Good, recalling Schutz's writings on 'ordinary reality', notes a similar concatenation of alienated personhood and fragmented temporality within the experience of American patients suffering from chronic pain:

In the everyday world, the self is experienced as the 'author' of its activities, as the 'originator' of on-going actions, and thus as an 'undivided total self'... In contrast, [Patient A] describes his body as having become an object distinct from or even alien to the experiencing and acting self. He articulated several dimensions to this objectification: The pain has agency. It is a demon, a monster lurking within, banging the insides of his body... For [Patient A], inner and outer time, what Schutz calls durée and cosmic time, seem out of synch. Even more terrifying, time itself seems to break down, to lose its ordering power... Past and present lose their order. Pain slows personal time, while outer time speeds by and is lost.' (Good 1994: 124-6, italics mine). ${ }^{14}$

Of course, for Good's interlocutor, temporal and social alienation is a distinctly personal conundrum and receives little institutional recognition, being precariously expressed within the contours of the individual body (see also Irving's description of the experiences of HIV/AIDS sufferers in this volume). In the ritual economies of Ladakh, this dislocation from the secure bulwarks of social existence follows instead the contours of the household and its associated economic structures, generating emergent but fractured geographies of temporal flow within Ladakhi communities.

The dependence of such distinctions on symbolic economy might cause us to reflect on our own complex constructions of political and cultural history. In Time and the Other, for example, Johannes Fabian draws polemic attention to the anthropological dichotomies of 'modern progressive time' and 'traditional static time' (Fabian 1983). Fabian sees this distinction as part of an imperialist 
tendency towards 'allochrony' - an image of fractured time that de-legitimizes the place of disempowered communities by 'removing' them from 'wider' economic and cultural histories. Does such 'allochrony' arise from a tendency to produce geographies of time similar in form to those evoked within the Ladakhi Buddhist case, in this case identifying whole cultures as agents 'outside' the legitimating historical agencies of Western civilization and economy? If so, then the rituals of time described above imply a politics of experience that is far wider than the intricacies of Tibetan Buddhist ritual, if rarely so precisely articulated. Indeed, while Fabian used his work to rail against the subtle injustices of allochrony in anthropological theory, the fracturing of time has often been evoked as an selfrepresentation of the very incarceration of the disempowered. Here, we might recall poet Sophia de Mello Breyner's evocation of the peaceful left-wing Carnation Revolution of 1974, 25 de Abril, when Portugal emerged from forty-eight years of dictatorship and political isolation:

This is the dawn I was waiting for

The first day whole and pure

When we emerged from night and silence

Alive into the substance of time. ${ }^{17}$

More germane to our topic, however: the ethnography of pollution and purification here militates against theoretical interpretations that privilege calendrical and astrological systems as models of or for social action in any directly deterministic fashion. The 'fracturing' of corporate social actors from established social time, and the ritualized strategies for re-establishing those hierarchical connections, necessitate a consideration of time-reckoning as an emergent 'social geography' and a consideration of ritual authority in maintaining the hegemonic place of 'cultural time' in particular social instances. As has been observed before, 'time' is rarely a fundamental and irreducible component of human social life, and we should therefore be wary of seeing it as the foundation of 'time-anthropology' itself. We should instead look elsewhere: most saliently, to the construction of agency (corporate or otherwise) within the wider milieu of social existence, or rather, as Good puts it, to 'the making and unmaking of the social world' (Good 1994: 134).

\section{Notes}

1. Thanks to Justin Kenrick, Keith Hart, Tim Ingold, Chris Knight, Elizabeth Hallam and Francesca Murphy for comments on this chapter at various stages 
of its production, and Olivia Harris, Nigel Rapport and Roy Dilley for a thought-provoking discussion of this topic.

2. This double-articulation of ideological hegemony is similar to Scott's rendition in Weapons of the Weak (1985: Ch.8): many people ascribe to power structures (such as taxation) in principle, and seek not to overthrow them through direct conflict; at the same time, they may seek to ensure through various tactics that the power-structure in question does not apply to them. However, see also n. 12 .

3. These two problems highlight the difficulty of seeing astrological systems as being unequivocal laws of cultural time. The significance of individual moments and events, and the consequences in terms of subsequent social action is highly negotiable, bringing together a range of often conflicting claims and interpretations within any one astrological pronouncement. In this regard, 'time' as an object of anthropological discourse has attendant upon it the kind of complexities that dogged the ethnography of kinship: a complex tension between our expectation of cultural laws, and our experience of cultural practice.

4. Mumford (1989: 97). The clearest example of this are the terma (hidden treasure) traditions, wherein prominent religious visionaries 'find' religious treasures such as texts and statues within the landscape (in rivers, rocks and temples), that were hidden by the 'second Buddha' Guru Rinpoche during the 'pure' time of Buddhism's infancy in Tibet (around $767 \mathrm{CE}$ ) and in anticipation of the dus-ngenpa (evil time) in which religion, morality and the Buddha's teaching would be eclipsed by decay. Those that find these hidden treasures are deemed tertons (treasure revealers), seen as reincarnations of Guru Rinpoche's early disciples. Such acts both constitute and contribute to the presence of chinlab, or 'blessing' within the present, degenerate world, implying a certain elasticity in local concepts of time. The most substantial such 'traces' can be seen in the be-yul tradition - valleys said to have been hidden from history during purer times, which reveal themselves to religious luminaries as sites for renewed religious practice.

5. The 'household' as a trope extends beyond the sphere of village households. It is also used to organize the structure of religious and monastic life, most particularly in the form of temples (lha-khang) as divine households (see Mills 2000).

6. Within the Tibetan astrological system, 'demonic time' can affect individuals, households and communities as wholes. The conjunction of certain planets can cause 'demonic' periods with reference to specific people, depending on their birth dates. More generally, certain events, such as solar and lunar eclipses, or the so-called 'day of the nine obstacles' (L. tsespa'i barchad rgu) were so profoundly inauspicious ( $m i$ tashi) that nothing of consequence would be 


\section{Martin Mills}

attempted, since it was bound to end in failure or worse. On the latter occasion, many people simply sat at home, neither visiting others nor being visited, doing nothing; all plans were postponed, and no business was carried out. Depending on the precise astrological cause, such events are generally polluting, and require extensive ritual purification. Indeed, certain traditions - such as the regularly performed Gya zhi rite, performed at the new year or on occasions of serious misfortune - are explicitly aimed at ameliorating the darker influences of specific temporal cycles (especially certain baleful planetary influences associated with the days of the week).

7. Intriguingly, Mary Douglas - in her celebrated work Purity and Danger - notes the same ambiguity in Old Testament understandings of deity: 'In the Old Testament we find blessing as the source of all good things, and the withdrawal of blessing as the source of all ills. The blessing of God makes the land possible for men to live in... Fertility of women, livestock and fields is promised as a result of the blessing and this is to be obtained by keeping covenant with God and observing all his precepts and ceremonies (Deut. xxviii, 1-4). Where the blessing is withdrawn and the power of the curse unleashed, there is barrenness, pestilence, confusion' (Douglas 1966: 49-50).

8. Death pollution practices are in principle similar, but purification of the living is interwoven with more complex rites given over to guiding the consciousness of the dead (Brauen 1982; Fremantle and Trungpa 1987; Mumford 1989: Ch.10).

9. See Brauen 1980; Kaplanian 1980; Phylactou 1989; Mills 2000. The p'aspun group dominate most marriage, birth and death ceremonial, and are said to be 'of one bone' (L. ruspa chig chig), that is, sharing the same patrilineal substance, although variations in the ritual and organizational structure of p'aspun groups in Ladakh and Zangskar are marked.

10. The use of 'lunar week' here refers to a calendrical week as a part of the monthly lunar calendar, which must occasionally be adjusted to link the waxing and waning of the moon to the actual passage of days. This sometimes means that a lunar week is longer or shorter than seven days (see Berzin 1991).

11. In certain cases, such as when birth has occurred during the 'slep' of the water spirits, the month-long seclusion may not be observed.

12. The combination of purification and offerings to divinities - the essential 'mechanism' for the eradication of pollution - is extremely common in Buddhist ritual, often included in ordinary daily rites, and larger consecration ceremonies (Sharpa Tulku and Perrott 1985).

13. This ritual separation from social time-ideologies is neither an opting-out nor a form of resistance, any more than a person who has lost his hands in an 


\section{Living in Time's Shadow}

accident is 'opting-out' of, or 'resisting' the social conventions concerning shaking hands at social gatherings.

14. Good later makes explicit parallels between the experience of chronic physical pain and the emotional pain associated with grief and mourning rites (Good 1994: 131). Thanks go to Liz Hallam for her comments on this subject.

15. Sophia de Mellow Breyner Andresen (1977), ' 25 de Abril', from $O$ nome das coisas, Trs. Ruth Fainlight in G. Benson et al. (eds), (1999), Poems on the Underground, London: Cassell.

\section{References}

Bloch, M. and J. Parry, (eds), (1982), Death and the Regeneration of Life, Cambridge: Cambridge University Press.

Butterfield, J. (ed.), (1999), The Arguments of Time, Oxford/New York: Oxford University Press for the British Academy.

Collingwood, R.G., (1993 [1946]), The Idea of History (revised with additional material, ed. W. J. v. d. Dussen), Oxford: Clarendon Press.

Davis, J. (1991), Times and Identities, Inaugural Lecture, Oxford: Oxford University Press.

___(1992) 'Tense in ethnography: some practical considerations', in Judith Okely and Helen Callaway (eds), Anthropology and Autobiography, London and New York: Routledge.

Dresch, P. and W. James (2000), 'Introduction: Fieldwork and the Passage of Time', in P. Dresch, W. James and D. Parkin (eds), Anthropologists in a Wider World: Essays on Field Research, Oxford/New York: Berghahn.

Dunbar, R., C. Knight and C. Power (eds), (1999), The Evolution of Culture, Edinburgh: Edinburgh University Press.

Fabian, J. (1983), Time and the Other: How Anthropology Makes its Object, New York: Columbia University Press.

_- (1991), Time and the Work of Anthropology: Critical Essays, Reading: Harwood Academic Publishers.

Evans-Pritchard, E.E. (1950), 'Social anthropology: past and present', the Marett Lecture (reprinted in his Essays in Social Anthropology, London: Faber, 1962.

Gell, A. (1992),The Anthropology of Time: Cultural Constructions of Temporal Maps and Images, Oxford: Berg.

__ (1998), Art and Agency: An Anthropological Theory, Oxford: Oxford University Press.

Gingrich, A., E. Ochs and A. Swedlund (eds), (2002), 'Repertoires of timekeeping in anthropology', Special Issue, supplement to Current Anthropology 43. 


\section{Martin Mills}

Harvey, D. (1989), The Condition of Postmodernity: An Enquiry into the Origins of Cultural Change, Oxford: Blackwell.

Hertz, R. (1960 [1907]), 'A contribution to the study of the collective representation of death', in his Death and the Right Hand, trs. R. and C. Needham, London: Cohen \& West.

Hobsbawm, E. and T.O. Ranger, (eds), (1983), The Invention of Tradition, Cambridge: Cambridge University Press.

Hubert, H. (1999 [1905]), Essay on Time: A Brief Study of the Representation of Time in Religion and Magic, trs. R. Parkin and J. Redding, Oxford: Berghahn. James, W. (1998). 'Mauss in Africa: On Time, History and Politics', in W. James and N.J. Allen (eds), Marcel Mauss: A Centenary Tribute, Oxford: Berghahn.

Knight, C.D. (1991), Blood Relations: Menstruation and the Origins of Culture, New Haven, CN: Yale University Press.

Leach, E.R (1961), Rethinking Anthropology, London: Athlone.

Legesse, Asmarom (1973), Gada: Three Approaches to the Study of African Society, New York: Free Press.

Munn, N. (1992), 'The cultural anthropology of time', Annual Review of Anthropology 21: 93-123.

Needham, R. (1967), 'Percussion and transition', Man 2: 606-25.

Radcliffe-Brown, A.R. (1952), Structure and Function in Primitive Society, London: Cohen \& West.

Sahlins, M. (1974), 'The original affluent society', Chapter 1 in Stone Age Economics, London: Tavistock.

Turner, V.W. (1969), The Ritual Process: Structure and Anti-Structure, Chicago: Aldine.

Van Gennep, A. (1960 [1909]), The Rites of Passage, London: Routledge \& Kegan Paul.

Warnock, M. (1994), Imagination and Time, Oxford: Blackwell.

Weber, M. (1958 [1904]), The Protestant Ethic and the Spirit of Capitalism, New York: Charles Scribner. 